\title{
Self-Reported Sleep Duration and Its Correlates with Sociodemographics, Health Behaviours, Poor Mental Health, and Chronic Conditions in Rural Persons 40 Years and Older in South Africa
}

\author{
Karl Peltzer ${ }^{1,2, *(1)}$ and Supa Pengpid ${ }^{2,3}$ \\ 1 HIV/AIDS/STIs and TB (HAST), Human Sciences Research Council, Pretoria 0001, South Africa \\ 2 Department of Research and Innovation, University of Limpopo, Sovenga 0727, South Africa; \\ supaprom@yahoo.com \\ 3 ASEAN Institute for Health Development, Mahidol University, Salaya 73170, Thailand \\ * Correspondence: k.peltzer@hsrc.ac.za; Tel.: +27-(0)12-302-2000
}

Received: 30 May 2018; Accepted: 27 June 2018; Published: 28 June 2018

\begin{abstract}
This study aims to investigate sleep duration and its association with sociodemographic, health behaviour, mental health, and chronic disease factors among rural individuals 40 years and older in South Africa. Cross-sectional data from the "Health and Aging in Africa: A Longitudinal Study of an INDEPTH community in South Africa" (HAALSI) baseline survey were analysed. Socio-demographic, clinical, health, and sleep duration data were collected. The total sample included 4725 persons 40 years and older (mean age 61.5 years, $\mathrm{SD}=13.0$, age range of $40-111$ years) in one sub-district in rural South Africa. The mean sleep duration was $8.28 \pm 1.93 \mathrm{~h}$. Short $(<7 \mathrm{~h})$ and long ( $\geq 9 \mathrm{~h}$ ) sleepers accounted for $13.1 \%$ and $40.0 \%$ of the sample, respectively. In adjusted multinomial logistic regression, greater wealth status $(p<0.05)$, inadequate fruit and vegetable consumption $(p<0.001)$, and depressive symptoms $(p<0.05)$ were associated with a higher odds and physical inactivity $(p<0.05)$ with a lower odds of short sleep duration. Being male $(p<0.001)$ and depressive symptoms $(p<0.001)$ were associated with a higher odds and being 50 to 69 years old $(p<0.01)$, having Grade 1 to 11 education $(p<0.05)$, and greater wealth status $(p<0.001)$ were associated with a lower odds of long sleep duration. In adjusted multinomial logistic regression, compared to normal sleepers, long sleepers were more likely to have myocardial infarction $(p<0.05)$. In unadjusted analysis, compared to normal sleepers, short sleepers were more likely to have cataracts $(p<0.05)$. This study found that a significant proportion of rural dwellers 40 years and older in South Africa had a short sleep duration and a high proportion had a long sleep duration. Some associations, such as depression and myocardial infarction, with short and/or long sleep duration were confirmed, while no associations were found for many chronic conditions.
\end{abstract}

Keywords: sleep duration; health behaviour; mental health; chronic conditions; persons 40 years and older; rural South Africa; HAALSI

\section{Introduction}

In several studies, older age has been found to be associated with a shorter sleep duration [1-3]. The National Sleep Foundation recommended seven to eight hours sleep for persons 65 years and older, considering better mental and physical health outcomes [4]. Short sleep duration $(\leq 6 \mathrm{~h})$ has been linked with negative health outcomes, including cardiovascular diseases, ischemic heart disease, hypertension, diabetes mellitus, poor mental health, chronic obstructive pulmonary disease (COPD), chronic gastroenteritis/peptic ulcer, multimorbidity, and mortality [5-10]. There has also 
been evidence that links a long sleep duration ( $\geq 9 \mathrm{~h}$ over a $24 \mathrm{~h}$ period) in adults and older adults with morbidity (e.g., hypertension, diabetes, cardiovascular disease, cerebrovascular diseases, stroke, atrial fibrillation, poor general health, poor mental health, hyperlipidemia, urolithiasis, multi-morbidity) and mortality $[4,8-13]$.

Regarding studies on sleep duration in Africa, the mean sleep duration in a national sample of individuals 50 years and older in South Africa was $8.6 \mathrm{~h} \mathrm{[12]} \mathrm{and} \mathrm{in} \mathrm{Ghana,} \mathrm{it} \mathrm{was} 7.7 \mathrm{~h} \mathrm{[14].} \mathrm{In} \mathrm{another}$ study, in a sample of rural and urban community dwelling adults in Ghana, the objectively measured total sleep time was, on average, $7.6 \mathrm{~h}$, which was a little lower than the average self-reported sleep time per night $(7.8 \mathrm{~h})$ [15]. The prevalence of short sleep $(\leq 6 \mathrm{~h})$ in a national study on persons 50 years and older in South Africa was $11.4 \%$ and the prevalence of long sleep ( $\geq 9 \mathrm{~h}$ ) was $43.5 \%$ [12]. In the study about community dwelling adults in Ghana, the objectively measured prevalence of short sleep $(\leq 6 \mathrm{~h})$ was $29.3 \%$ and long sleep ( $\geq 9 \mathrm{~h}$ ) was $38.4 \%$ [15].

Sociodemographic factors (older age, female sex) and lifestyle factors (inadequate fruit intake, current tobacco use, and physical inactivity) have also been found to be associated with a short sleep duration $[8,9,12]$, and sociodemographic factors (older age, younger age, higher education) and lifestyle factors (inadequate fruit intake, current smoking, alcohol use, physical inactivity) have been associated with long sleep $[8,9,12]$. Investigating the association between sleep duration and chronic conditions may contribute to the understanding of mortality that is related to unhealthy sleep duration [8].

This study aims to investigate sleep duration and its association with sociodemographic, health behaviour, mental health, and chronic disease factors among rural middle-older South Africans. It was hypothesized that sleep duration differs by different health outcomes.

\section{Materials and Methods}

\subsection{Sample and Procedure}

Baseline data were analysed from the "Health and Ageing in Africa: A Longitudinal Study of an INDEPTH Community in South Africa (HAALSI) in the INDEPTH Health and Demographic Surveillance System (HDSS) site of Agincourt" in rural South Africa [16]. From the selected 6281 men and women, 5059 completed home interviews (response rate 85.9\%) [16] and 4725 completed assessments of sleep duration; those with incomplete sleep duration assessment were excluded from the analysis. Trained field workers also collected blood through finger pricks and prepared dried bloodspots (DBS) from each participant who consented to blood collection. The study was conducted in 2015. Signed informed consent was obtained from all respondents prior to assessments. The study received ethical approvals from the University of the Witwatersrand Human Research Ethics Committee (ref. M141159), the Harvard T.H. Chan School of Public Health, Office of Human Research Administration (ref. C13-1608-02), and the Mpumalanga Provincial Research and Ethics Committee. [16].

\subsection{Measures}

Sleep duration was assessed with the question, "Over the past four weeks, how many hours do you think you actually slept each day?" [17] We followed a similar categorization used by previous studies and classified sleep hours into three categories: short sleep ( $<7 \mathrm{~h}$ per day), normal sleep $(7-8 \mathrm{~h})$, and long sleep ( $\geq 9 \mathrm{~h}$ per day) [18].

Sociodemographic variables included age, sex, formal education, and a wealth index in quintiles created from household characteristics and ownership of household items, livestock, and vehicles [16].

\subsubsection{Health Behaviour and Mental Health Variables}

Current tobacco use was assessed with two questions on current smoking and current smokeless tobacco use, such as snuff, chewing tobacco, snus, and betel with tobacco [16]. 
Alcohol dependence was assessed with the four-item "Cut down-Annoyed-Guilty-Eye opener" (CAGE) questionnaire [19]. For example, "Have you ever felt you should cut down on your drinking?" Item responses to the CAGE are scored 0 or 1 , with scores of 2 or more indicating alcohol dependence [19] (Cronbach's alpha 0.82).

Fruit and vegetable consumption were assessed with two questions, "How many servings of fruit/vegetables do you eat on a typical day? (on any one day)" (with the help of show-cards) [16]. Inadequate fruit and vegetable consumption was classified as having less than five servings a day.

Physical activity was measured using the validated General Physical Activity Questionnaire (GPAQ) [20,21]. It assessed days and duration of physical activity at work, for transport, and during leisure time in a usual week. Results were classified into low, moderate, and high physical activity according to GPAQ guidelines [21].

Body Mass Index (BMI) was calculated from standardized body height and weight measures, and classified into underweight $\left(<18.5 \mathrm{~kg} / \mathrm{m}^{2}\right)$, normal weight $\left(18.5-24.9 \mathrm{~kg} / \mathrm{m}^{2}\right)$, overweight $\left(25-29.9 \mathrm{~kg} / \mathrm{m}^{2}\right)$, and obesity $\left(30+\mathrm{kg} / \mathrm{m}^{2}\right)$, using World Health Organization (WHO) criteria [22].

Depression symptoms were screened using the Center for Epidemiological Studies-Depression Scale (CES-D) eight-item questionnaire, with a cut-off of three or more symptoms signifying depressive symptoms [23] (Cronbach's alpha 0.66).

Posttraumatic Stress Disorder (PTSD) was screened using a seven-item symptom scale developed by Breslau et al. [24], with scores of four or more indication caseness for PTSD symptoms (Cronbach's alpha 0.83).

\subsubsection{Chronic Conditions}

Hypertension was measured with three blood pressure readings (averaging the last two measurements) and classified if "systolic blood pressure was greater than or equal to $140 \mathrm{mmHg}$ or diastolic blood pressure was $90 \mathrm{mmHg}$ or higher, or if use of anti-hypertensive medication was reported at the time of interview" [16].

Dyslipidaemia was classified as "those who meet at least one of the following criteria: total cholesterol $>6.21 \mathrm{mmol} / \mathrm{L}$, HDL-C $<1.19 \mathrm{mmol} / \mathrm{L}$, LDL-C $>4.1 \mathrm{mmol} / \mathrm{L}$, triglycerides $>2.25 \mathrm{mmol} / \mathrm{L}$, reported ever diagnosed with high cholesterol, or if use of medication is reported at the time of interview" [16].

Diabetes was classified with "fasting glucose (defined as $>8 \mathrm{~h})>7 \mathrm{mmol} / \mathrm{L}(126 \mathrm{mg} / \mathrm{dL}$ ) or non-fasting glucose level $>11.0 \mathrm{mmol} / \mathrm{L}(200 \mathrm{mg} / \mathrm{dL})$, reported ever being diagnosed with diabetes, or if use of medication is reported at the time of interview" [16].

Anaemia was classified as "a blood haemoglobin concentration of $<13 \mathrm{~g} / \mathrm{dL}$ for men or $<12 \mathrm{~g} / \mathrm{dL}$ for women" [25].

Stroke, angina, cataracts, heart failure, kidney disease, myocardial infarction, HIV, and tuberculosis were assessed by self-reported diagnosis [16].

Chronic bronchitis was assessed based on symptoms reported [26].

Multi-morbidity was defined as having two to 13 of the above 13 chronic conditions.

\subsection{Data Analysis}

Descriptive statistics were used to describe the sample and sleep duration levels. Associations between sociodemographic, health behaviour, and mental health variables and short and long sleep duration were calculated using unconditional multinomial logistic regression. The independent association of 13 chronic conditions with short and long sleep duration was assessed with multinomial logistic regression analysis, after adjusting for age, sex, education, wealth status, tobacco use, alcohol dependence, physical inactivity, inadequate fruit and vegetable consumption, BMI body weight, depression, and PTSD symptoms. No collinearity was detected and missing values were excluded from the analysis. $p<0.05$ was considered significant. All statistical procedures were done with STATA software version 13.0 (Stata Corporation, College Station, TX, USA). 


\section{Results}

\subsection{Sample Characteristics}

The total sample included 4725 adults 40 years and older (mean age 61.5 years, $\mathrm{SD}=13.0$, age range of 40-111 years) in rural South Africa. Sample characteristics are described in Table 1. The mean sleep duration was $8.28 \pm 1.93 \mathrm{~h}$. Short and long sleepers accounted for $13.1 \%$ and $40.0 \%$ of the sample, respectively (see Table 1 ).

Table 1. Sample characteristics.

\begin{tabular}{|c|c|c|c|c|c|}
\hline Variable & Sample & Short Sleepers & Normal Sleepers & Long Sleepers & Statistics \\
\hline & $N(\%)$ & $\%$ & $\%$ & $\%$ & $\%$ \\
\hline \multicolumn{6}{|l|}{ Sociodemographics } \\
\hline \multicolumn{6}{|l|}{ Age (years) } \\
\hline $40-49$ & 867 (18.3) & 12.5 & 47.9 & 39.7 & $<0.001$ \\
\hline $50-59$ & $1338(28.3)$ & 14.6 & 59 & 35.4 & \\
\hline 80 or more & $489(10.3)$ & 8.6 & 39.7 & 51.7 & \\
\hline \multicolumn{6}{|l|}{ Sex } \\
\hline Female & $2513(53.2)$ & 13.3 & 48.5 & 38.2 & 0.024 \\
\hline Male & $2212(46.8)$ & 12.8 & 45.1 & 42.1 & \\
\hline \multicolumn{6}{|l|}{ Formal education } \\
\hline \multicolumn{6}{|l|}{ Wealth index } \\
\hline Poor & $956(20.2)$ & 11.1 & 42.1 & 46.9 & $<0.001$ \\
\hline Second poorest & 928 (19.6) & 10.9 & 44.4 & 44.7 & \\
\hline Medium & $932(19.7)$ & 13 & 48.6 & 38.4 & \\
\hline Second richest & $938(19.9)$ & 15.5 & 49 & 35.5 & \\
\hline Rich & 971 (20.6) & 14.8 & 50.4 & 34.8 & \\
\hline \multicolumn{6}{|l|}{ Health variables } \\
\hline \multicolumn{6}{|l|}{ Body Mass Index (BMI) $\left(\mathrm{kg} / \mathrm{m}^{2}\right)$} \\
\hline$<18.5$ & $241(5.5)$ & 11.6 & 44.8 & 43.6 & 0.457 \\
\hline 18.5 to $<25$ & $1604(36.6)$ & 12.2 & 47.3 & 40.5 & \\
\hline 25 to $<30$ & $1230(28.1)$ & 13.9 & 46.6 & 39.5 & \\
\hline
\end{tabular}

\subsection{Chronic Conditions and Multi-Morbidity by Sleep Duration Categories}

Table 2 describes the prevalence of 13 chronic conditions and multi-morbidity by sleep duration categories. The prevalence of having cataracts was significantly higher in short sleepers than normal sleepers and myocardial infarction was significantly higher in long sleepers than normal sleepers (see Table 2).

\subsection{Factors Associated with Short and Long Sleep Duration}

In adjusted multinomial logistic regression, greater wealth status, inadequate fruit and vegetable consumption, and depressive symptoms were positively, and physical inactivity negatively, associated with short sleep duration. Being male and having depressive symptoms increased the odds, and being 50 to 69 years old, having Grade 1 to 11 education, and greater wealth status decreased the odds, of long sleep duration (see Table 3). 
Table 2. Chronic diseases by sleep duration groups.

\begin{tabular}{|c|c|c|c|c|c|}
\hline Variable & Total & Short Sleepers & Normal Sleepers & Long Sleepers & Statistics \\
\hline & $N(\%)$ & $\%$ & $\%$ & $\%$ & \\
\hline Anaemia & 727 (17.4) & $88(12.1)$ & $334(45.9)$ & $305(42.0)$ & 0.229 \\
\hline Angina & $109(2.3)$ & $9(8.3)$ & $45(41.3)$ & $55(50.5)$ & 0.057 \\
\hline Cataract & $610(12.9)$ & $99(16.2)$ & $286(46.9)$ & $225(36.9)$ & 0.028 \\
\hline Chronic bronchitis & $70(1.5)$ & $6(8.6)$ & $30(42.9)$ & $34(48.6)$ & 0.268 \\
\hline Diabetes & $528(12.2)$ & $66(12.5)$ & $254(48.1)$ & $208(39.4)$ & 0.907 \\
\hline Dyslipidaemia & $1728(43.6)$ & $218(12.6)$ & $839(48.6)$ & $671(38.8)$ & 0.291 \\
\hline Heart failure & $33(0.7)$ & $5(15.2)$ & $12(36.4)$ & $16(48.5)$ & 0.475 \\
\hline Hypertension & $2697(58.6)$ & $354(13.1)$ & $1293(47.9)$ & $1050(38.9)$ & 0.215 \\
\hline Kidney disease & $193(4.1)$ & $19(9.8)$ & $92(47.7)$ & $82(42.5)$ & 0.387 \\
\hline Myocardial infarction & $20(0.4)$ & $2(10.0)$ & $4(20.0)$ & $14(70.0)$ & 0.021 \\
\hline Stroke & $135(2.9)$ & $16(11.9)$ & $67(49.6)$ & $52(38.5)$ & 0.795 \\
\hline HIV & $586(12.5)$ & $88(15.0)$ & $270(46.1)$ & $228(38.9)$ & 0.320 \\
\hline Tuberculosis & $418(8.9)$ & $62(14.8)$ & $205(49.0)$ & $151(36.1)$ & 0.191 \\
\hline \multicolumn{6}{|c|}{ Number of chronic conditions } \\
\hline 0 & $455(12.1)$ & $64(14.1)$ & $215(47.3)$ & $176(38.7)$ & 0.511 \\
\hline 1 & $1198(31.8)$ & $166(13.9)$ & $544(45.4)$ & $488(40.7)$ & \\
\hline$\geq 2$ & $2116(56.1)$ & $284(13.4)$ & $1028(48.6)$ & $804(38.0)$ & \\
\hline
\end{tabular}

Table 3. Associations between sociodemographic and health factors in relation to sleep duration.

\begin{tabular}{|c|c|c|c|c|}
\hline \multirow[t]{2}{*}{ Variable } & \multicolumn{2}{|c|}{ Short $(<7$ h) vs. Normal (7-8 h) Sleepers } & \multicolumn{2}{|c|}{ Long $(\geq 9$ h) vs. Normal (7-8 h) Sleepers } \\
\hline & COR & AOR & COR & AOR \\
\hline \multicolumn{5}{|l|}{ Sociodemographics } \\
\hline \multicolumn{5}{|l|}{ Age (years) } \\
\hline $40-49$ & 1 (Reference) & 1 (Reference) & 1 (Reference) & 1 (Reference) \\
\hline $50-59$ & $1.13(0.86,1.47)$ & $1.08(0.80,1.49)$ & $0.85(0.71,1.03)$ & $0.70(0.56,0.88) * *$ \\
\hline $60-69$ & $1.05(0.80,1.38)$ & $1.07(0.75,1.51)$ & $0.94(0.78,1.13)$ & $0.70(0.55,0.89) * *$ \\
\hline $70-79$ & $1.22(0.90,1.65)$ & $1.35(0.91,1.99)$ & $1.27(1.03,1.56) *$ & $0.90(0.69,1.18)$ \\
\hline 80 or more & $0.83(0.56,1.24)$ & $1.01(0.60,1.70)$ & $1.57(1.24,1.99)^{* * *}$ & $1.12(0.80,1.55)$ \\
\hline \multicolumn{5}{|l|}{ Sex } \\
\hline Female & 1 (Reference) & 1 (Reference) & 1 (Reference) & 1 (Reference) \\
\hline Male & $1.04(0.87,1.25)$ & $1.01(0.81,1.27)$ & $1.18(1.05,1.34)^{* *}$ & $1.32(1.13,1.55)^{* * *}$ \\
\hline \multicolumn{5}{|l|}{ Formal education } \\
\hline None & 1 (Reference) & 1 (Reference) & 1 (Reference) & 1 (Reference) \\
\hline Grade 1-7 & $1.18(0.97,1.45)$ & $1.16(0.91,1.49)$ & $0.77(0.67,0.89) * * *$ & $0.84(0.70,0.99) *$ \\
\hline Grade 8-11 & $0.89(0.66,1.20)$ & $0.74(0.51,1.09)$ & $0.69(0.56,0.85)^{* * *}$ & $0.69(0.53,0.89)^{* *}$ \\
\hline Grade 12 or more & $1.12(0.83,1.53)$ & $1.11(0.72,1.72)$ & $0.62(0.49,0.78)^{* * *}$ & $0.78(0.57,1.08)$ \\
\hline \multicolumn{5}{|l|}{ Wealth index } \\
\hline Poor & 1 (Reference) & 1 (Reference) & 1 (Reference) & 1 (Reference) \\
\hline Second poorest & $0.90(0.69,1.26)$ & $1.15(0.80,1.65)$ & $0.90(0.75,1.10)$ & $0.91(0.72,1.14)$ \\
\hline Medium & $0.71(0.76,1.36)$ & $1.28(0.90,1.81)$ & $0.71(0.59,0.86)^{* * *}$ & $0.64(0.51,0.81)^{* * *}$ \\
\hline Second richest & $0.65(0.90,1.59)$ & $1.41(0.99,2.00)$ & $0.65(0.54,0.79) * * *$ & $0.68(0.54,0.87) * *$ \\
\hline Rich & $0.62(0.84,1.48)$ & $1.45(1.01,2.08)$ * & $0.62(0.51,0.75)^{* * *}$ & $0.63(0.49,0.80)^{* * *}$ \\
\hline \multicolumn{5}{|l|}{ Health variables } \\
\hline \multicolumn{5}{|l|}{ Body Mass Index (BMI) $\left(\mathrm{kg} / \mathrm{m}^{2}\right)$} \\
\hline 18.5 to $<25$ & 1 (Reference) & 1 (Reference) & 1 (Reference) & 1 (Reference) \\
\hline$<18.5$ & $1.00(0.64,1.56)$ & $0.97(0.58,1.63)$ & $1.13(0.85,1.51)$ & $0.99(0.70,1.41)$ \\
\hline 25 to $<30$ & $1.15(0.92,1.46)$ & $1.23(0.94,1.60)$ & $0.99(0.84,1.16)$ & $1.09(0.90,1.31)$ \\
\hline$\geq 30$ & $1.04(0.83,1.31)$ & $1.10(0.83,1.45)$ & $0.90(0.77,1.05)$ & $1.07(0.88,1.30)$ \\
\hline Current tobacco use & $1.19(0.94,1.57)$ & $1.28(0.95,1.72)$ & $1.05(0.85,1.19)$ & $0.80(0.66,1.01)$ \\
\hline Alcohol dependence & $1.89(0.96,3.71)$ & $1.57(0.72,3.41)$ & $1.27(0.73,2.19)$ & $0.81(0.41,1.60)$ \\
\hline Fruit and vegetable consumption ( $<5$ servings) & $1.82(1.31,2.52)^{* * *}$ & $2.02(1.36,3.02)^{* * *}$ & $0.98(0.82,1.18)$ & $0.95(0.76,1.19)$ \\
\hline Physical activity (low) & $0.83(0.69,0.99) *$ & $0.80(0.64,0.99) *$ & $1.24(1.09,1.40)^{* * *}$ & $1.12(0.96,1.31)$ \\
\hline Depressive symptoms & $1.22(0.96,1.55)$ & $1.34(1.01,1.79) *$ & $1.32(1.12,1.56)^{* * *}$ & $1.41(1.15,1.74)^{* * *}$ \\
\hline PTSD symptoms & $1.96(0.70,1.59)$ & $1.23(0.76,1.99)$ & $0.99(0.74,1.32)$ & $1.06(0.74,1.51)$ \\
\hline \multicolumn{5}{|l|}{ Number of chronic conditions } \\
\hline 0 & 1 (Reference) & 1 (Reference) & 1 (Reference) & 1 (Reference) \\
\hline 1 & $1.03(0.74,1.72)$ & $0.99(0.70,1.39)$ & $1.10(0.87,1.38)$ & $0.99(0.70,1.44)$ \\
\hline$\geq 2$ & $0.93(0.68,1.26)$ & $0.86(0.62,1.19)$ & $0.96(0.77,1.19)$ & $0.94(0.74,1.19)$ \\
\hline
\end{tabular}

COR $=$ Crude Odds Ratio; AOR = Adjusted Odds Ratio; ${ }^{* * *} p<0.001 ;{ }^{* *} p<0.01 ;{ }^{*} p<0.05$. 


\subsection{Associations between Chronic Conditions and Sleep Duration}

In adjusted multinomial logistic regression, compared to normal sleepers, long sleepers were more likely to have myocardial infarction. In unadjusted analysis, compared to normal sleepers, short sleepers were more likely to have cataracts, but the association with cataracts did not persist after adjustment (see Table 4).

Table 4. Associations between chronic conditions and sleep duration.

\begin{tabular}{|c|c|c|c|c|}
\hline \multirow[t]{2}{*}{ Chronic Condition } & \multicolumn{2}{|c|}{ Short ( $<7$ h) vs. Normal (7-8 h) Sleepers } & \multicolumn{2}{|c|}{ Long ( $\geq 9$ h) vs. Normal (7-8 h) Sleepers } \\
\hline & COR & AOR $^{1}$ & COR & AOR $^{1}$ \\
\hline Anaemia & $0.92(0.72,1.19)$ & $0.89(0.67,1.17)$ & $1.12(0.95,1.33)$ & $1.10(0.91,1.32)$ \\
\hline Angina & $0.71(0.35,1.47)$ & $0.78(0.37,1.64)$ & $1.44(0.97,2.15)$ & $1.51(0.97,2.35)$ \\
\hline Cataract & $1.29(1.01,1.65)^{*}$ & $1.24(0.94,1.63)$ & $0.91(0.76,1.10)$ & $0.81(0.66,1.00)$ \\
\hline Chronic bronchitis & $0.72(0.30,1.73)$ & $0.68(0.28,1.67)$ & $1.33(0.81,2.19)$ & $1.21(0.72,2.02)$ \\
\hline Diabetes & $0.94(0.71,1.26)$ & $0.90(0.66,1.23)$ & $0.97(0.80,1.18)$ & $0.95(0.77,1.18)$ \\
\hline Dyslipidaemia & $0.87(0.72,1.06)$ & $0.83(0.67,1.02)$ & $0.92(0.81,1.06)$ & $0.91(0.78,1.05)$ \\
\hline Heart failure & $1.50(0.53,4.28)$ & $1.22(0.39,3.89)$ & $1.57(0.84,3.32)$ & $1.45(0.65,3.25)$ \\
\hline Hypertension & $0.98(0.81,1.18)$ & $0.93(0.76,1.14)$ & $0.90(0.79,1.02)$ & $0.87(0.76,1.01)$ \\
\hline Kidney disease & $0.73(0.44,1.21)$ & $0.68(0.40,1.16)$ & $1.05(0.77,1.42)$ & $1.05(0.76,1.46)$ \\
\hline Myocardial infarction & $1.80(0.33,9.84)$ & $2.13(0.35,12.95)$ & $4.12(1.36,12.55) *$ & $4.11(1.13,14.98)$ * \\
\hline Stroke & $0.85(0.49,1.48)$ & $0.71(0.37,1.39)$ & $0.91(0.63,1.31)$ & $0.82(0.52,1.28)$ \\
\hline HIV & $1.20(0.93,1.55)$ & $1.22(0.92,1.62)$ & $0.99(0.82,1.19)$ & $1.10(0.90,1.35)$ \\
\hline Tuberculosis & $1.10(0.81,1.48)$ & $1.05(0.76,1.46)$ & $0.85(0.68,1.06)$ & $0.86(0.68,1.09)$ \\
\hline
\end{tabular}

$\mathrm{COR}=$ Crude Odds Ratio; AOR $=$ Adjusted Odds Ratio ${ }^{1}$ Adjusted for age, sex, education, wealth status, tobacco use, alcohol dependence, physical inactivity, inadequate fruit and vegetable consumption, BMI body weight, depression, and PTSD symptoms; * $p<0.05$.

\section{Discussion}

The study focused on investigating the prevalence and correlates of short and long sleep duration in middle- and older-aged individuals in rural South Africa. The mean sleep duration was $8.3 \mathrm{~h}$, which is similar to a previous national study among individuals 50 years and older in South Africa $(8.6 \mathrm{~h})$ [12], but lower than in a national study on persons 50 years and older in Ghana (7.7 h), China $(7.6 \mathrm{~h})$, and India $(7.1 \mathrm{~h})$ [25]. The prevalence of short sleep (13.1\%), was similar to the national study on persons 50 years and older in South Africa (11.4\%) [12], but was lower than in individuals 50 years and older in China (20.3\%) and India (29.3\%) [27], and the prevalence of long sleep (40.0\%) was similar to the national study on persons 50 years and older in South Africa (43.5\%) [12], but was higher than in individuals 50 years and older in China (25.9\%) and India (14.9\%) [27].

In unadjusted analysis, the prevalence of long sleep increased with age, but this was no longer the case in the adjusted analysis. There were no age differences in short sleep. Similar results were found in the national study persons 50 years and older in South Africa [12]. There were also no gender differences in short sleep, but men had a higher prevalence of long sleep than women did. Such differences were not found in the national study of persons 50 years and older South Africa [12]. In persons 50 years and older in six countries, women reported a longer mean sleep duration than men [14]. This sample consisted of rural dwellers in South Africa and it is possible that traditional gender roles lead to lower demands on men and an increase in sleeping duration. This study found that greater wealth status was associated with a higher odds of short sleep and lower odds of long sleep. It is possible that those with a better economic status work longer hours, have greater job responsibility, greater perceived stress, and more depressive symptoms, which may affect the sleep duration negatively [28,29].

Consistent with a previous systematic review [10], having depressive symptoms was associated with both short and long sleep. Since this was a cross-sectional study, we could not determine the direction of the association. Zhai et al. [10] found in their review of prospective studies that both short and long sleep are a risk for the development of depression. Contrary to expectation [8], this study found a weak negative association between physical inactivity and short sleep. This finding calls for 
further investigations. Some studies $[8,9,12]$ found that various health risk behaviours were associated with short and/or long sleep, while this study only found a positive association between inadequate fruit and vegetable consumption and short sleep duration. Mechanisms that may mediate associations between short sleep and inadequate fruit and vegetable consumption may be multi-factorial [8,9]. It is possible that an inadequate diet increases the risk for chronic diseases, which in turn can affect sleep duration [30]. Unlike some previous studies [8,9], this study did not find an association between multi-morbidity and short and/or long sleep.

Regarding specific chronic conditions, this study only found an association between myocardial infarction and long sleep and in an unadjusted analysis, cataracts and short sleep, while there no associations for anaemia, angina, chronic bronchitis, diabetes, dyslipidaemia, heart failure, hypertension, kidney disease, stroke, HIV, and TB. Various studies have confirmed the relationship between cardiovascular conditions such as myocardial infarction with long sleep [4,8-13]. In a study in Ghana, sleep duration was also not associated with the prevalence of cardiovascular disorders [15]. Wang et al. [8] also did not find an association between anaemia, diabetes, and short and/or long sleep. This study did not confirm findings from previous studies on the association between hypertension, diabetes mellitus, ischemic heart disease, COPD, multimorbidity, and short sleep [5-10], and the association between hypertension, diabetes, cardiovascular disease, hyperlipidaemia, cerebrovascular diseases, multi-morbidity, and long sleep [4,8,9,11-13]. The lack of associations found in this study may be attributed to the low prevalence of short sleep and very high prevalence of long sleep. It could also be that rural individuals 40 years and older in this sample in South Africa use adaptive coping strategies to deal with their stress and thus, better their health and reduce the risk for cardio-metabolic disorders [6].

\section{Limitations of the Study}

The self-reported assessment of sleep duration has its limitations. Self-reported sleep duration may be an overestimation of the actual measured sleep duration [15,31]. This may contribute in explaining the large proportion of long sleepers. Several other relevant sleep-related indicators, such as the use of hypnotic medications, shift work, and environmental and cultural factors, were not assessed in this study, which could have increased the understanding of the relationship chronic conditions and sleep duration, and should be assessed in future studies. Furthermore, this study was based on cross-sectional data in one sub-district in rural South Africa, hindering causative conclusions and generalizations beyond the study district.

\section{Conclusions}

This study found a significant proportion with short sleep and a high proportion with long sleep among 40 years and older rural dwellers in South Africa. Potential factors associated with the risk for short and long sleep duration are related to sociodemographic and lifestyle factors. Some associations, such as depression and myocardial infarction, with short and/or long sleep duration were confirmed, while no associations were found with many chronic conditions. Further, (longitudinal) studies are need to gain a better understanding of possible associations.

Author Contributions: K.P. and S.P. designed the analysis, analysed the data, wrote the manuscript, and approved the final paper.

Funding: This research received no external funding.

Acknowledgments: "HAALSI (Health and Aging in Africa: A Longitudinal Study of an INDEPTH Community in South Africa) is sponsored by the National Institute on Aging (grant number 1P01AG041710-01A1) and is conducted by the Harvard Center for Population and Development Studies in partnership with Witwatersrand University. The Agincourt HDSS was supported by the Wellcome Trust, UK, (058893/Z/99/A, 069683/Z/02/Z, $085477 / Z / 08 / Z$ and085477/B/08/Z), the University of the Witwatersrand and South African Medical Research Council."

Conflicts of Interest: The authors declare no conflict of interest. 


\section{References}

1. Crowley, K. Sleep and sleep disorders in older adults. Neuropsychol. Rev. 2011, 21, 41-53. [CrossRef] [PubMed]

2. Patel, S.R.; Malhotra, A.; Gottlieb, D.J.; White, D.P.; Hu, F.B. Correlates of long sleep duration. Sleep 2006, 29, 881-889. [CrossRef] [PubMed]

3. Gu, D.; Sautter, J.; Pipkin, R.; Zeng, Y. Sociodemographic and health correlates of sleep quality and duration among very old Chinese. Sleep 2010, 33, 601-610. [CrossRef] [PubMed]

4. Hirshkowitz, M.; Whiton, K.; Albert, S.M.; Alessi, C.; Bruni, O.; DonCarlos, L.; Hazen, N.; Herman, J.; Adams Hillard, P.J.; Katz, E.S.; et al. National sleep foundation's updated sleep duration recommendations: Final report. Sleep Health J. Natl. Sleep Found. 2015, 1, 233-243. [CrossRef] [PubMed]

5. Itani, O.; Jike, M.; Watanabe, N.; Kaneita, Y. Short sleep duration and health outcomes: A systematic review, meta-analysis, and meta-regression. Sleep Med. 2016, 32, 246-256. [CrossRef] [PubMed]

6. Anujuo, K.; Stronks, K.; Snijder, M.B.; Jean-Louis, G.; Rutters, F.; van den Born, B.J.; Peters, R.J.; Agyemang, C. Relationship between short sleep duration and cardiovascular risk factors in a multi-ethnic cohort-The helius study. Sleep Med. 2015, 16, 1482-1488. [CrossRef] [PubMed]

7. Pandey, A.; Williams, N.; Donat, M.; Ceide, M.; Brimah, P.; Ogedegbe, G.; McFarlane, S.I.; Jean-Louis, G. Linking sleep to hypertension: Greater risk for blacks. Int. J. Hypertens. 2013, 2013, 436502. [CrossRef] [PubMed]

8. Wang, S.; Wu, Y.; Ungvari, G.S.; Ng, C.H.; Forester, B.P.; Gatchel, J.R.; Chiu, H.F.K.; Kou, C.; Fu, Y.; Qi, Y.; et al. Sleep duration and its association with demographics, lifestyle factors, poor mental health and chronic diseases in older Chinese adults. Psychiatry Res. 2017, 257, 212-218. [CrossRef] [PubMed]

9. Wang, S.; Li, B.; Wu, Y.; Ungvari, G.S.; Ng, C.H.; Fu, Y.; Kou, C.; Yu, Y.; Sun, H.Q.; Xiang, Y.T. Relationship of sleep duration with sociodemographic characteristics, lifestyle, mental health, and chronic diseases in a large chinese adult population. J. Clin. Sleep Med. 2017, 13, 377-384. [CrossRef] [PubMed]

10. Zhai, L.; Zhang, H.; Zhang, D. Sleep duration and depression among adults: A meta-analysis of prospective studies. Depress. Anxiety 2015, 32, 664-670. [CrossRef] [PubMed]

11. Jike, M.; Itani, O.; Watanabe, N.; Buysse, D.J.; Kaneita, Y. Long sleep duration and health outcomes: A systematic review, meta-analysis and meta-regression. Sleep Med. Rev. 2018, 39, 25-36. [CrossRef] [PubMed]

12. Peltzer, K. Sociodemographic and health correlates of sleep problems and duration among older adults in South Africa. S. Afr. J. Psychiatry 2012, 18, 150-156. [CrossRef]

13. Krittanawong, C.; Tunhasiriwet, A.; Wang, Z.; Zhang, H.; Farrell, A.M.; Chirapongsathorn, S.; Sun, T.; Kitai, T.; Argulian, E. Association between short and long sleep durations and cardiovascular outcomes: A systematic review and meta-analysis. Eur. Heart J. Acute Cardiovasc. Care 2017, 2048872617741733. [CrossRef]

14. Gildner, T.E.; Liebert, M.A.; Kowal, P.; Chatterji, S.; Snodgrass, J.J. Associations between sleep duration, sleep quality, and cognitive test performance among older adults from six middle-income countries: Results from the Study on Global Ageing and Adult Health (SAGE). J. Clin. Sleep Med. 2014, 10, 613-621. [CrossRef] [PubMed]

15. Cole, H.V.; Owusu-Dabo, E.; Iwelunmor, J.; Newsome, V.; Meeks, K.; Agyemang, C.; Jean-Louis, G. Sleep duration is associated with increased risk for cardiovascular outcomes: A pilot study in a sample of community dwelling adults in Ghana. Sleep Med. 2017, 34, 118-125. [CrossRef] [PubMed]

16. Gómez-Olivé, F.X.; Montana, L.; Wagner, R.G.; Kabudula, C.W.; Rohr, J.K.; Kahn, K.; Bärnighausen, T.; Collinson, M.; Canning, D.; Gaziano, T.; et al. Cohort profile: Health and Ageing in Africa: A longitudinal study of an INDEPTH Community in South Africa (HAALSI). Int. J. Epidemiol. 2018, 47, 689-690. [CrossRef] [PubMed]

17. Buysse, D.J.; Reynolds, C.F.; Monk, T.H.; Berman, S.R.; Kupfer, D.J. The Pittsburgh sleep quality index: A new instrument for psychiatric practice and research. Psychiatry Res. 1989, 28, 193-213. [CrossRef]

18. Petrov, M.E.; Lichstein, K.L. Differences in sleep between black and white adults: An update and future directions. Sleep Med. 2016, 18, 74-81. [CrossRef] [PubMed]

19. Ewing, J.A. Detecting alcoholism: The CAGE questionnaire. JAMA 1984, 252, 1905-1907. [CrossRef] [PubMed]

20. Armstrong, T.; Bull, F. Development of the World Health Organization Global Physical Activity Questionnaire (GPAQ). J. Public Health 2006, 14, 66-70. [CrossRef]

21. World Health Organisation (WHO). Global Physical Activity Surveillance. 2009. Available online: http: / / www.who.int/chp/steps/GPAQ/en/index.html (accessed on 2 December 2018). 
22. World Health Organization (WHO). Obesity: Preventing and Managing the Global Epidemic-Report of a WHO Consultation; World Health Organization: Geneva, Switzerland, 2000.

23. Radloff, L.S. The CES-D scale: A self-report depression scale for research in the general population. Appl. Psychol. Meas. 1977, 1, 385-401. [CrossRef]

24. Breslau, N.; Peterson, E.L.; Kessler, R.C.; Schultz, L.R. Short screening scale for DSM-IV posttraumatic stress disorder. Am. J. Psychiatry 1999, 156, 908-911. [CrossRef] [PubMed]

25. Shisana, O.; Labadarios, D.; Rehle, T.; Simbayi, L.; Zuma, K. South African National Health and Nutrition Examination Survey (SANHANES-1); Human Sciences Research Council Press: Cape Town, South Africa, 2013.

26. Mejza, F.; Gnatiuc, L.; Buist, A.S.; Vollmer, W.M.; Lamprecht, B.; Obaseki, D.O.; Nastalek, P.; Nizankowska-Mogilnicka, E.; Burney, P.G.J.; BOLD study collaborators. Prevalence and burden of chronic bronchitis symptoms: Results from the BOLD study. Eur. Respir. J. 2017, 50, 1700621. [CrossRef] [PubMed]

27. Selvamani, Y.; Arokiasamy, P.; Chaudhary, M. Association of sleep problems and sleep duration with self-rated health and grip strength among older adults in India and China: Results from the study on global aging and adult health (SAGE). J. Public Health 2018. [CrossRef]

28. Jackson, C.L.; Redline, S.; Kawachi, I.; Williams, M.A.; Hu, F.B. Racial disparities in short sleep duration by occupation and industry. Am. J. Epidemiol. 2013, 178, 1442-1451. [CrossRef] [PubMed]

29. Johnson, D.A.; Lisabeth, L.; Lewis, T.T.; Sims, M.; Hickson, D.A.; Samdarshi, T.; Taylor, H.; Diez Roux, A.V. The Contribution of psychosocial stressors to sleep among African Americans in the Jackson heart study. Sleep 2016, 39, 1411-1419. [CrossRef] [PubMed]

30. Dashti, H.S.; Scheer, F.A.; Jacques, P.F.; Lamon-Fava, S.; Ordovás, J.M. Short sleep duration and dietary intake: Epidemiologic evidence, mechanisms, and health implications. Adv. Nutr. 2015, 6, 648-659. [CrossRef] [PubMed]

31. Lauderdale, D.S.; Knutson, K.L.; Yan, L.L.; Liu, K.; Rathouz, P.J. Sleep duration: How well do self-reports reflect objective measures? The CARDIA Sleep Study. Epidemiology 2008, 19, 838-845. [CrossRef] [PubMed]

(C) 2018 by the authors. Licensee MDPI, Basel, Switzerland. This article is an open access article distributed under the terms and conditions of the Creative Commons Attribution (CC BY) license (http:/ / creativecommons.org/licenses/by/4.0/). 